\title{
A Giant Cell Fibroma and Focal Fibrous Hyperplasia in a Young Child: A Case Report
}

\author{
Rodney J. Vergotine \\ Department of Pediatric Dentistry, University of Illinois at Chicago, Chicago, IL 60607, USA \\ Correspondence should be addressed to Rodney J. Vergotine, rodney@uic.edu
}

Received 1 March 2012; Accepted 12 April 2012

Academic Editors: A. C. B. Delbem, A. Epivatianos, and L. Junquera

Copyright () 2012 Rodney J. Vergotine. This is an open access article distributed under the Creative Commons Attribution License, which permits unrestricted use, distribution, and reproduction in any medium, provided the original work is properly cited.

A case of two fibrotic lesions of the oral mucosa in a 17-month-old African-American female is reported. Both lesions occurred on the anterior maxilla, one lesion pedunculated on the buccal attached gingiva and the other lesion sessile on the palate. Histological examination characterized the buccal lesion as focal fibrous hyperplasia (FFH) and the palatal lesion as a giant cell fibroma (GCF). A case is made for continuing the consideration of GCF as a histologically distinct entity from FFH but that no difference in clinical impact between the two lesions exists.

\section{Introduction}

Focal fibrous hyperplasia or fibroma is considered the most common benign soft tissue growth in the oral cavity $[1,2]$. This lesion has a predilection for females, occurs in patients older than 30 years, is a few centimeters in diameter, pedunculated or sessile, and occurs frequently on the gingiva or buccal mucosa. Chronic irritation or trauma is frequently identified as the causative factor. Treatment of the fibroma involves surgical excision, and recurrences are very infrequent. In 1974 Weathers and Callihan identified a distinct entity within previously identified fibroma lesions. This was called the giant cell fibroma, a lesion that is specifically distinguished by the presence of stellate/giant cells on histological examination $[3,4]$. The GCF has an equal sex distribution, tends to occur among 20+-year olds, and occurs most often in Caucasians. Houston presented further validation for this lesion in 1982 [5]. A number of authors have disputed the need for the classification of the GCF as a separate entity from the fibroma. They based their conclusions on the fact that stellate and multinucleated cells are found at various stages of maturation of the lesion and that other histological features are not sufficiently unusual or characteristic to warrant identification as a distinct entity [6-9]. Most current pathology literature identifies these two lesions as distinct entities [10]. The purpose of this paper is to present a case in which both a giant cell fibroma and focal fibrous hyperplasia presented in the same patient at the same time.

\section{Case Report}

A 17-month-old African-American girl was referred from her private dentist for evaluation of two papillomatous lesions in the anterior maxilla (Figure 1). History revealed a healthy child, the product of a normal, uncomplicated fullterm pregnancy. Dental history revealed that the growths first appeared 5 months ago and were slowly increasing in size. No history of dental and/or facial trauma was reported. The child was not in any pain, and no interference with feeding was reported by the mother.

The lesion on the buccal mucosa was about 1 centimeter in size, pink in color, stippled and attached via a peduncle to the attached gingiva opposite tooth no. 51 and tooth no. 52 . The lesion blanched slightly with digital pressure.

The lesion of the palate was about $0.75 \mathrm{~cm}$ in size, circular, pink in color, stippled, sessile, and adjacent to the incisive papilla between tooth no. 51 and tooth no. 52. No blanching was noted with slight digital pressure.

A radiograph of the area revealed no bony involvement (Figure 2). 


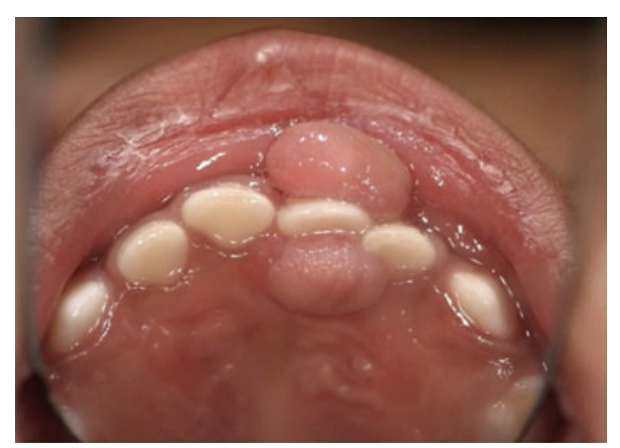

FIgURE 1: Buccal and palatal lesions.



FIgURE 2: Radiographic image with palatal lesion circled.

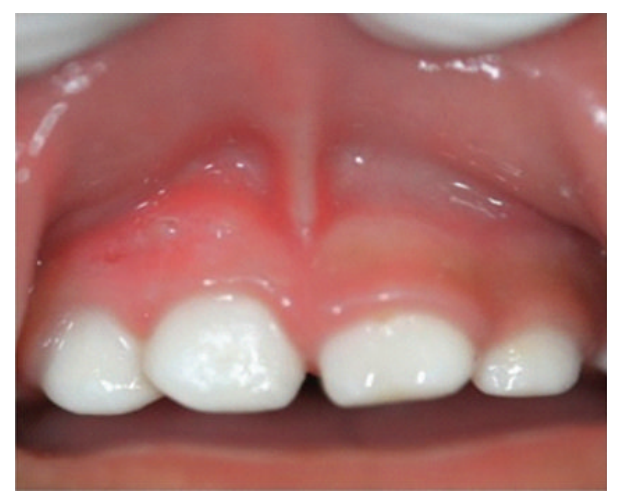

(a)



(b)

FIGURE 3: One-week postoperative pictures.
Due to the age of the patient and the relative complexity of the procedure, it was decided to perform excisional biopsy of both lesions under general anesthesia. The lesions were excised utilizing a number 11 scalpel blade. The excised areas were then cauterized.

On one-week followup both areas were healing well; no pain or discomfort and no difficulty in eating were reported by the mother (Figure 3 ).

2.1. Differential Diagnosis. Table 1 includes most of the lesions that should be considered in the differential diagnosis of both lesions. An attempt is made to order the lesions ranging from the most likely to the least likely to occur in this specific patient.

2.2. Histology. Buccal lesion-dense fibrous connective tissue surfaced by stratified squamous epithelium with a normal maturation pattern. No evidence of malignancy. Diagnosis of focal fibrous hyperplasia (Figure 4).

Palatal lesion-dense fibrous connective tissue surfaced by stratified squamous epithelium with a normal maturation pattern. Many stellate fibroblasts and long thin rete pegs are present. Diagnosis of giant cell fibroma (Figure 5).

The pathology report also suggested that since there were only subtle histological differences between the two lesions, they might have simply been in different stages of maturation. The report also advised that the child be assessed now and in the future for additional lesions and to consider and rule out fibromatosis syndrome.

\section{Discussion}

As the most common nonneoplastic growth in the oral cavity, much has been written about the fibroma (FFH). The identification of a GCF as a separate entity by Weathers and Callihan added a new dimension to the discussion $[3,4]$. The clinical presentation and epidemiology of most nonneoplastic growths in the oral cavity are quite similar; thus identification is dependant on histopathological differentiation. In this case report, two clinically distinct lesions presented in the same patient. As an African-American infant, this patient was outside the normal epidemiological predictors for the presentation of either lesion. The presentation of both types of lesion in the same patient has not been reported previously in the literature. The mother reported a 5-month period of observation of especially the buccal lesion. The similar size of the two lesions and the young age of the patient suggest that lifetime of the two lesions was similar. This would make a case for the Weathers and Callihan postulate that GCF is a separate entity and not merely a different presentation based on maturation of the lesion. Regezi et al. found that the presence of stellate cells is dependant on the pattern of collagen in the lamina propria and that stellate cells are most often found in oral lesions presenting on the gingiva or palate where the submucosa consists mainly of lamina propria [8]. Given the preponderance of lamina propria in the locations of these lesions, they should both have presented with stellate cells, according to Regezi et al. The fact 


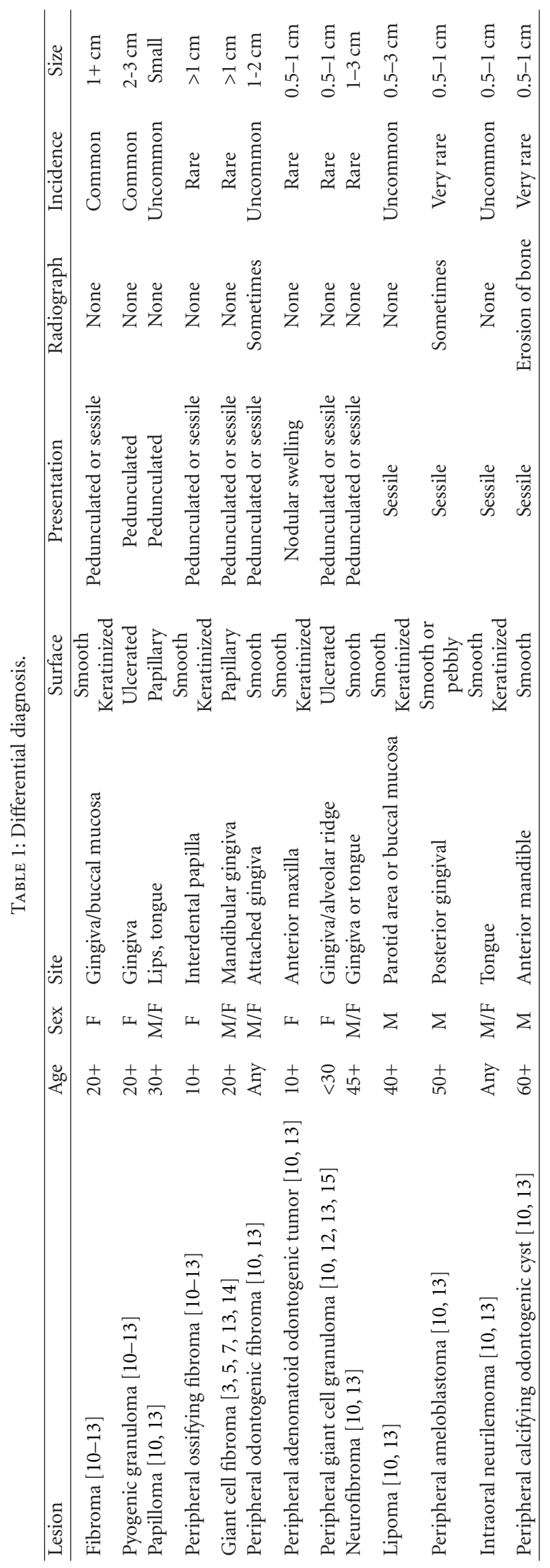




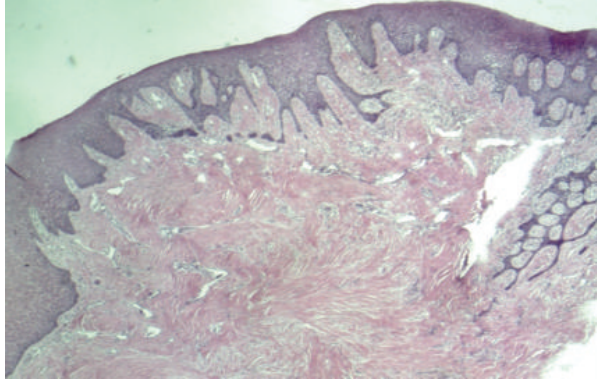

Low magnification-stratified squamous epithelium

(a)

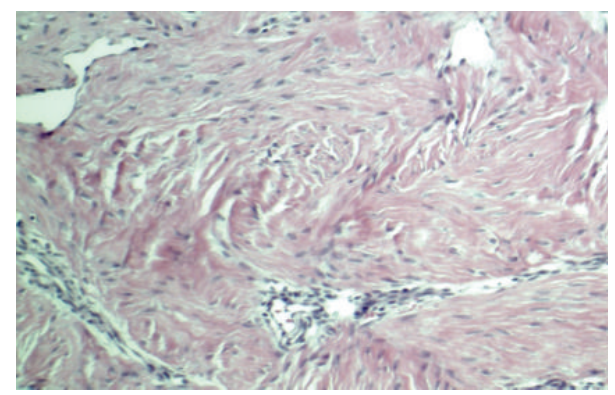

Medium magnification-dense fibrous connective tissue

(b)

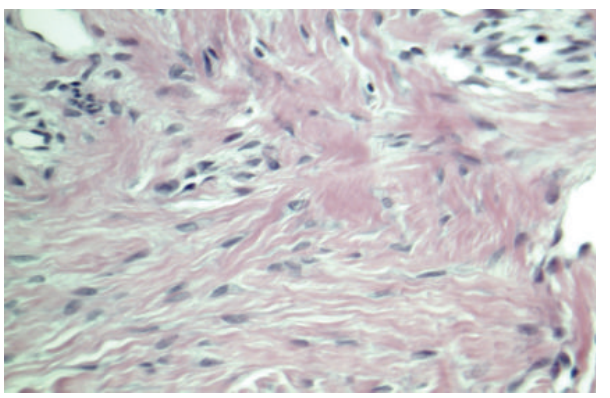

High magnification-multiple fibroblasts

(c)

FIGURE 4: Histology slides of buccal lesion-focal fibrous hyperplasia (Fibroma).

that only one of the lesions presented with stellate cells gives further credence to the Weathers and Callihan postulate that GCF is a separate entity. The detractors for the identification of GCF as a separate entity also note that the proposed treatment, possible causative factors, and recurrence rate for both lesions are identical. On a histopathological level, GCF and FFH are distinct; on a clinical level the difference is insignificant. It is much more important to distinguish FFH/GCF from other nonneoplastic lesions that could have impact on developing structures or bone. This case report illustrates that clinical impact of these two lesions is similar and that on a patient care level making the histopathological distinction did not alter treatment.

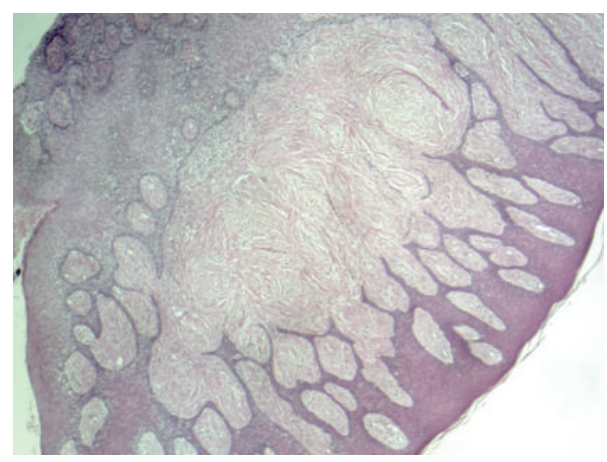

Long magnification-stratified squamous epithelium

(a)

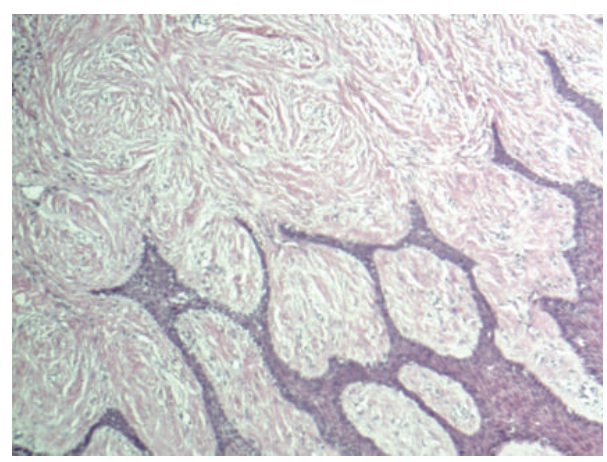

Medium magnification-long thin rete pegs.

(b)



High magnification-dense fibrous connective tissue

(c)

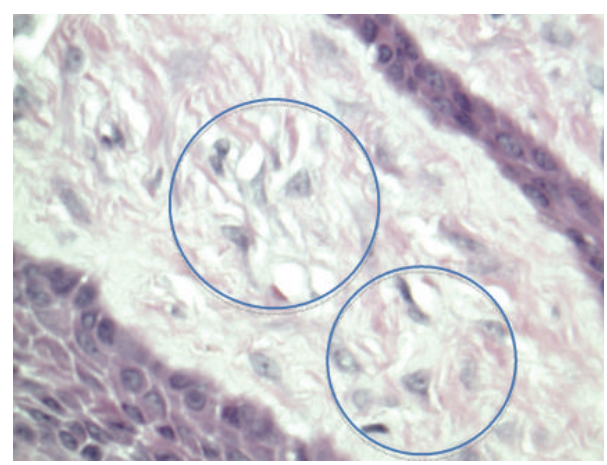

Ultrahigh magnification-stellate giant cells

(d)

Figure 5: Histology slides of palatal lesion—giant cell fibroma. 


\section{Conclusions}

Multiple fibrotic lesions can concurrently occur in young children.

GCF as a separate entity from FFH can be established histologically.

Treatment of the FFH and GCF is identical.

\section{References}

[1] T. Esmeili, F. Lozada-Nur, and J. Epstein, "Common benign oral soft tissue masses," Dental Clinics of North America, vol. 49, no. 1, pp. 223-240, 2005.

[2] Y. Kfir, A. Buchner, and L. S. Hansen, "Reactive lesions of the gingiva. A clinicopathological study of 741 cases," Journal of Periodontology, vol. 51, no. 11, pp. 655-661, 1980.

[3] D. R. Weathers and M. D. Callihan, "Giant cell fibroma," Oral Surgery Oral Medicine and Oral Pathology, vol. 37, no. 3, pp. 374-384, 1974.

[4] D. R. Weathers and W. G. Campbell, "Ultrastructure of the giant cell fibroma of the oral mucosa," Oral Surgery Oral Medicine and Oral Pathology, vol. 38, no. 4, pp. 550-561, 1974.

[5] G. D. Houston, "The giant cell fibroma. A review of 464 cases," Oral Surgery Oral Medicine and Oral Pathology, vol. 53, no. 6, pp. 582-587, 1982.

[6] J. Reibel, "Oral fibrous hyperplasias containing stellate and multinucleated cells," Scandinavian Journal of Dental Research, vol. 90, no. 3, pp. 217-226, 1982.

[7] N. W. Savage and P. A. Monsour, "Oral fibrous hyperplasias and the giant cell fibroma.," Australian dental journal, vol. 30, no. 6, pp. 405-409, 1985.

[8] J. A. Regezi, R. M. Courtney, and D. A. Kerr, "Fibrous lesions of the skin and mucous membranes which contain stellate and multinucleated cells," Oral Surgery Oral Medicine and Oral Pathology, vol. 39, no. 4, pp. 605-614, 1975.

[9] L. H. Bakos, "The giant cell fibroma: a review of 116 cases," Annals of dentistry, vol. 51, no. 1, pp. 32-35, 1992.

[10] B. W. Neville, D. D. Damm, C. M. Allen, and J. E. Bouquot, Oral and Maxillofacial Pathology, W.B. Saunders, St. Louis, Mo, USA, 3rd edition, 2009.

[11] W. Zhang, Y. Chen, Z. An, N. Geng, and D. Bao, "Reactive gingival lesions: a retrospective study of 2,439 cases," Quintessence International, vol. 38, no. 2, pp. 103-110, 2007.

[12] A. Buchner, A. Shnaiderman-Shapiro, and M. Vered, "Pediatric localized reactive gingival lesions: a retrospective study from israel," Pediatric Dentistry, vol. 32, no. 7, pp. 486-492, 2010.

[13] S. K. Shah, M. C. Le, and W. M. Carpenter, "Retrospective review of pediatric oral lesions from a dental School biopsy service," Pediatric Dentistry, vol. 31, no. 1, pp. 14-19, 2009.

[14] M. M. Braga, A. L. G. Carvalho, M. C. P. Vasconcelos, P. H. Braz-Silva, and S. L. Pinheiro, "Giant cell fibroma: a case report," Journal of Clinical Pediatric Dentistry, vol. 30, no. 3, pp. 261-264, 2006.

[15] M. D. Martins, F. Pires, F. Daleck, S. I. Myaki, M. N. P. Friggi, and M. A. T. Martins, "Peripheral giant cell granuloma in anterior maxilla: case report in a child," Journal of Clinical Pediatric Dentistry, vol. 30, no. 2, pp. 161-164, 2005. 


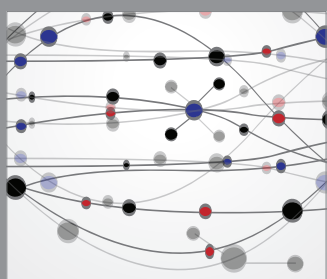

The Scientific World Journal
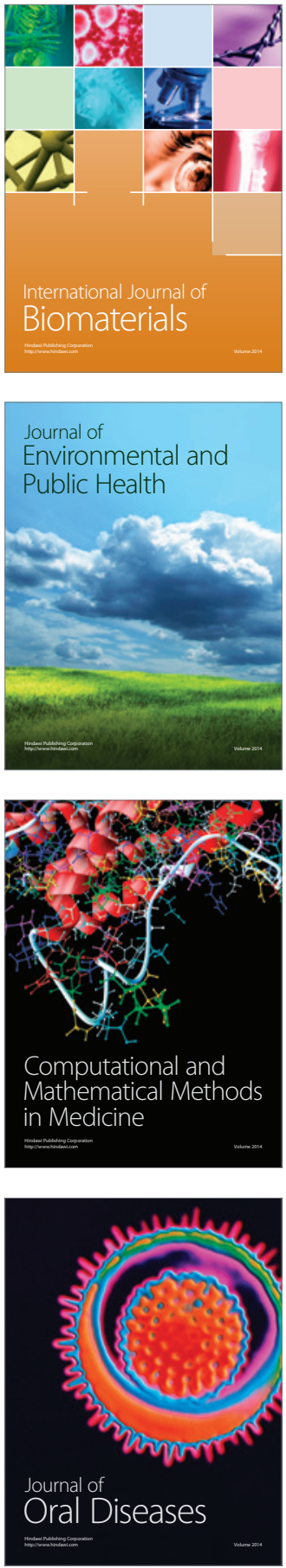
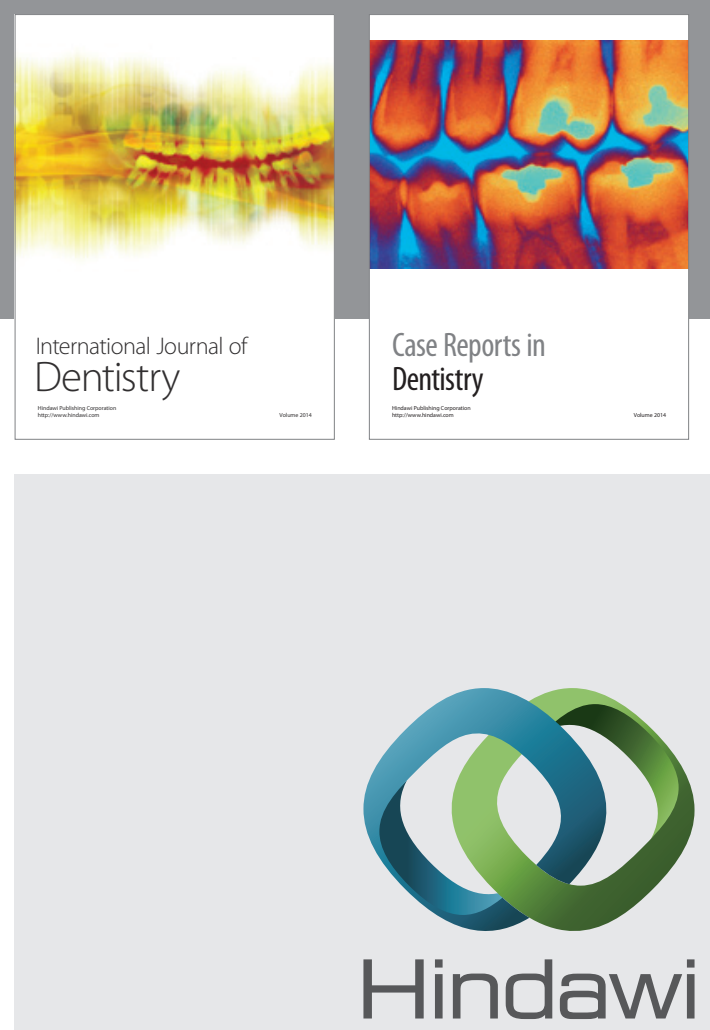

Submit your manuscripts at

http://www.hindawi.com

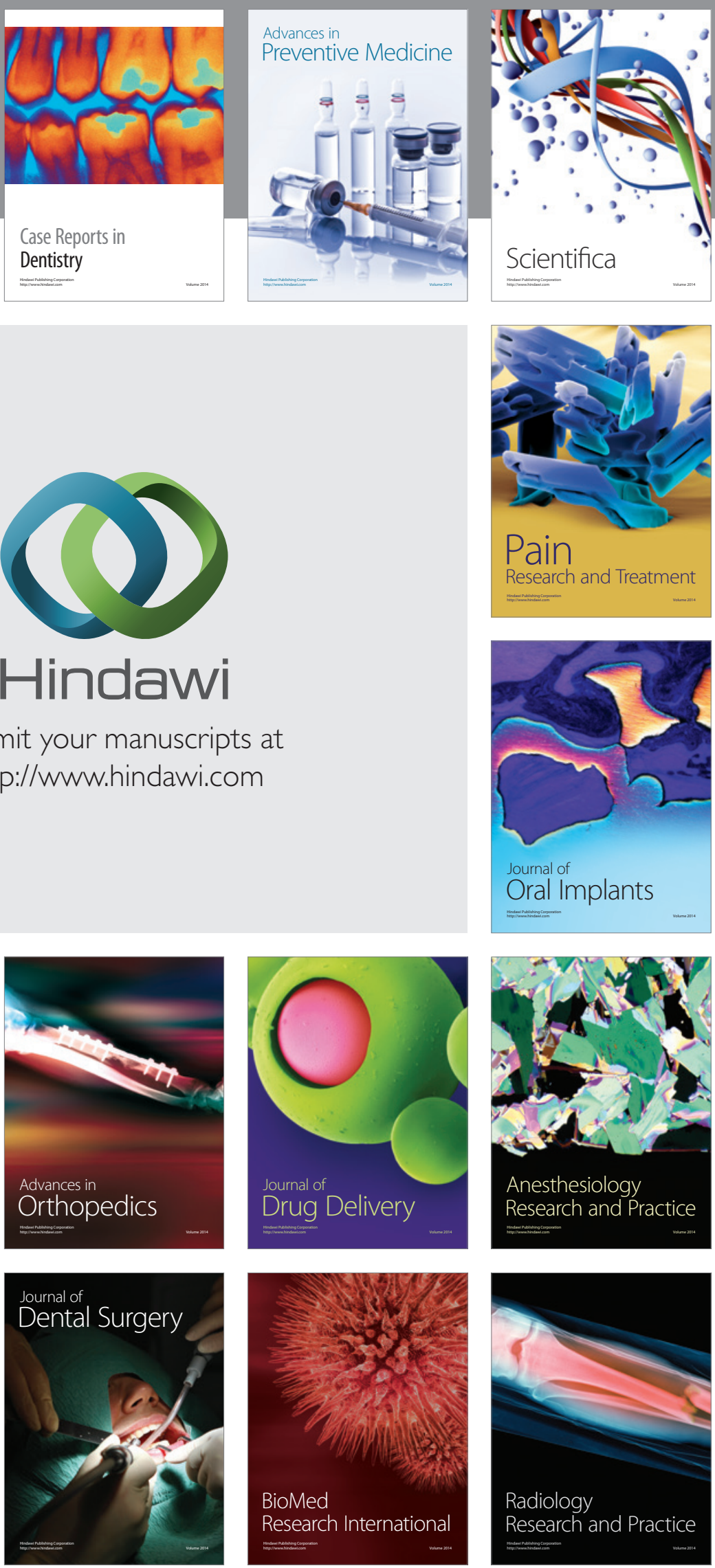